\title{
Implicações da multiplicidade de atribuições para a saúde da mulher
}

\author{
Implication of multiplicity of assignments on women's health \\ Implicaciones de la multiplicidad de atribuciones para la salud de las mujeres
}

Recebido: 09/09/2021 | Revisado: 17/09/2021 | Aceito: 23/09/2021 | Publicado: 24/09/2021

Isabela Flávia dos Santos

ORCID: https://orcid.org/0000-0002-6564-1138 Universidade Federal de São João del Rei, Brasil E-mail: isabelaflasantos@gmail.com

Luciana Netto

ORCID: https://orcid.org/0000-0001-6573-5006 Universidade Federal de São João del Rei, Brasil E-mail: luciananetto@ufsj.edu.br

\begin{abstract}
Resumo
A cada dia, a mulher tem ampliado suas conquistas, porém, além da possibilidade de inserção no mercado de trabalho e nos estudos, elas levaram consigo diversas outras atribuições, como as responsabilidades domésticas e o ato de cuidar dos filhos e familiares, o que se constitui em um grande desafio. Consciente dessa realidade torna-se necessário melhor entendimento das condições de vida e saúde das mulheres, em seu aspecto integral. Nesse contexto, o objetivo desse estudo é compreender os efeitos da multiplicidade de atribuições para a saúde da mulher. Trata-se de um estudo exploratório, de abordagem qualitativa, ancorado no referencial teórico-metodológico da dialética. Questionário semiestruturado e entrevistas foram realizadas junto a 17 mulheres com faixa etária entre 20 e 59 anos, que possuíam multiplicidade de atribuições. Os dados foram analisados pelo conteúdo, na perspectiva de Bardin. Os dados empíricos revelaram que as atribuições que mais influenciam na saúde das mulheres foram as que comportam a relação com a casa e afazeres domésticos, com os filhos e família, e com o trabalho. A flexibilização e o autocuidado se mostram como desafio para a preservação do bem-estar e qualidade de vida e manutenção do equilíbrio físico, social e mental.
\end{abstract}

Palavras-chave: Saúde da Mulher; Promoção da saúde; Enfermagem; Qualidade de vida.

\begin{abstract}
Every day, women have expanded their achievements, however, in addition to the possibility of insertion in the labor market and in studies, they took with them several other attributions, such as domestic responsibilities and the act of taking care of children and family, which constitutes a great challenge. Aware of this reality, it is necessary to better understand the conditions of life and health of women, in its integral aspect. In this context, the objective of this study is to understand the effects of the multiplicity of attributions for women's health. It is an exploratory study, with a qualitative approach, anchored in the theoretical-methodological framework of dialectics. Semi-structured questionnaire and interviews were carried out with 17 women aged between 20 and 59 years, who had multiple roles. The data were analyzed by content, in Bardin's perspective. The empirical data revealed that the attributions that most influence the health of women were those that involve the relationship with the house and household chores, with the children and family, and with work. Flexibility and self-care are a challenge for the preservation of well-being and quality of life and maintenance of physical, social and mental balance.
\end{abstract}

Keywords: Women's health; Health promotion; Nursing; Quality of life.

\begin{abstract}
Resumen
Cada día, las mujeres han ampliado sus logros, sin embargo, además de la posibilidad de inserción en el mercado laboral y en los estudios, se llevaron consigo varias otras atribuciones, como las responsabilidades domésticas y el acto de cuidar a los hijos y la familia, que constituye un gran desafío. Conscientes de esta realidad, es necesario comprender mejor las condiciones de vida y salud de las mujeres, en su aspecto integral. En este contexto, el objetivo de este estudio es comprender los efectos de la multiplicidad de atribuciones para la salud de la mujer. Se trata de un estudio exploratorio, con enfoque cualitativo, anclado en el marco teórico-metodológico de la dialéctica. Se realizó cuestionario semiestructurado y entrevistas a 17 mujeres de entre 20 y 59 años, que tenían múltiples atribuciones. Los datos se analizaron por contenido, desde la perspectiva de Bardin. Los datos empíricos revelaron que las atribuciones que más influyen en la salud de las mujeres son las que involucran la relación con el hogar y las tareas del hogar, con los hijos y la familia, y con el trabajo. La flexibilidad y el autocuidado son un desafío para la preservación del bienestar y la calidad de vida y el mantenimiento del equilibrio físico, social y mental.
\end{abstract}

Palabras clave: La salud de la mujer; Promoción de la salud; Enfermería; Calidad de vida. 


\section{Introdução}

As mulheres representam a maior parte da população brasileira $(50,77 \%)$, e são as principais usuárias do Sistema Único de Saúde (SUS), frequentando os serviços de saúde por demanda própria de atendimento, mas, sobretudo, em acompanhamento a crianças, familiares, idosos e amigos, de quem são cuidadoras (Brasil, 2004; Piolli et al., 2018).

A situação de saúde envolve diversos aspectos de vida, com relação ao meio ambiente, moradia, renda, alimentação, condições de trabalho e lazer. As desigualdades sociais, econômicas e culturais mostram que o processo de adoecer e morrer das pessoas são particularmente diferenciados (Bezerra et al., 2018; Costa, 2018).Observa-se que o número de mulheres que vivem na pobreza é superior aos dos homens, o que se deve ao fato de elas usarem cerca de metade do tempo disponível em atividades do lar, não recebendo nada por esse serviço, diminuindo o acesso aos bens sociais, inclusive aos serviços de saúde, e também ao fato de em muitas vezes as mulheres receberem menos do que os homens para realizarem o mesmo serviço fora do domicílio. As mulheres vivem mais que os homens, porém adoecem com mais frequência, e a sua vulnerabilidade frente a certas doenças está relacionada principalmente com a situação de discriminação nas relações de trabalho e na sociedade, além da sobrecarga com as responsabilidades do trabalho doméstico, e outras atribuições, como cuidar de filhos (Brasil, 2004; Barreto, 2017; Heymann et al., 2019; Santos \& Diniz, 2018).

Nesse ínterim, na primeira metade da década de 1930 foram criadas políticas nacionais de saúde voltadas para a assistência à saúde da mulher, com intuito de minimizar as situações graves de saúde as quais as mulheres eram expostas, porém essas políticas eram limitadas à atenção relacionada à gravidez e ao parto. Os programas materno-infantis elaborados nas décadas posteriores, também traduziam uma visão restrita sobre a mulher, baseada em sua especificidade biológica e no seu papel social de mãe e doméstica, como o Programa de Assistência Integral à Saúde da Mulher (PAISM), criado em 1984 e, após duas décadas, ele foi reformulado na Política Nacional de Atenção Integral à Saúde da Mulher (PNAISM), incorporando a abordagem de gênero, integralidade e promoção da saúde, e hoje ajuda a consolidar avanços significativos no campo dos direitos sexuais, reprodutivos e da saúde da mulher (Brasil, 2004; Bhattacharya et al., 2019).

Percebe-se que, apesar do avanço no conceito de saúde da mulher, esse ainda fica restrito à saúde reprodutiva, e não trata das questões de saúde-doença, que são termos interligados e que levam em consideração o processo que determinam vários fatores socioeconômicos, culturais e históricos. Sabendo disso, a atenção integral, que constitui-se como um dos pilares da atenção básica, é baseada em ações de promoção, prevenção de agravos e recuperação da saúde, levando em conta os determinantes sociais (Brasil, 2004).

Nesse contexto, deve-se considerar a integralidade da saúde das mulheres, levando em conta que esse público é alvo constante de implicações de saúde. A maior vulnerabilidade feminina, principalmente em relação aos transtornos mentais, pode estar ligada à algumas especificidades biológicas, que diz respeito às alterações no sistema endócrino que ocorrem no período pré-menstrual, pós-parto e menopausa, e principalmente, aos aspectos sociais que apontam para uma incontestável diferença de gênero quanto a prevalência e incidência dos adoecimentos psíquicos. Além de transtornos psíquicos percebe-se também adoecimentos por fatores físicos, que se sucedem de consequências decorrentes de maus hábitos de vida (Heymann et al., 2019; Santos \& Diniz, 2018; Senicato et al., 2018; Pedrosa \& Zanello, 2016).

No que diz respeito às desigualdades de gênero, as mulheres vivem em um cenário que ainda possui muitas rupturas e permanências, seja no campo profissional, familiar e no campo das relações sociais, que traz como consequências as altas taxas de violência e feminicídios, além da sobrecarga de trabalho. A mulher, com o tempo, conseguiu alguns êxitos, como a autonomia concebida por meio da contracepção medicalizada e segura, rompendo, assim, com o determinismo social e biológico da maternidade, e a autonomia financeira pela inserção feminina no mercado de trabalho. Porém, ainda se vê muitas normas sociais impostas para as mulheres, como criar bem seus filhos, cuidar do ambiente doméstico, ganhar menos que os 
homens, e ser submissa (Bezerra et al., 2018; Barreto, 2017; Bhattacharya et al., 2019; Samosir et al., 2020; Vilela \& Lourenço, 2018; Hay et al., 2019).

Essas normas sociais levaram a mulher a um processo de reconhecimento e luta, onde elas buscaram espaço externo ao ambiente doméstico com o qual se identificassem, adentrando ao mercado de trabalho e assumindo posições que antes eram ocupadas somente por homens, porém não deixaram as responsabilidades para as quais foram educadas, principalmente para a maternidade e o cuidado doméstico. Nesse contexto, percebe-se que a mulher assumiu uma multiplicidade de atribuições, e sabendo disso, nos últimos anos têm-se estudado os aspectos relativos, e suas consequências para a saúde física e mental das mulheres (Bezerra et al., 2018; Barreto, 2017; Senicato et al., 2018; Samosir et al., 2020; Vilela et al., 2018; Hay et al., 2019).

O que se percebe é que a realidade social das mulheres é marcada por avanços significativos e grandes desafios. Nesse ínterim, vê-se que o diagnóstico atual de saúde das mulheres brasileiras, ainda se traduz em uma realidade distinta do almejado, apesar dos intensos investimentos na área. Nesse sentido, o Ministério da Saúde (MS), por meio do planejamento estratégico, destaca que a busca por avanços consiste em implementar um modelo de atenção a saúde da mulher que tenha como perspectiva a promoção da saúde, incentivando a autonomia e o protagonismo feminino (Brasil, 2004; Bhattacharya et al., 2019; Rabelo et al., 2019).

Sabendo dessa realidade, torna-se necessário melhor entendimento das condições de saúde das mulheres, relacionadas ao comportamento em relação à autonomia, ao autocuidado, alimentação, atividade física, autoestima, e demais aspectos do estilo de vida, além de comorbidades associadas. Conhecer a realidade dessas mulheres permite o planejamento de ações voltadas à saúde da mulher, de modo a minimizar o prejuízo para a qualidade de vida em todo o ciclo de vida feminino. Nesse contexto, este estudo buscou compreender os efeitos da multiplicidade de atribuições para a saúde da mulher, considerando os espaços público e privado.

\section{Metodologia}

Trata-se de um estudo exploratório, de abordagem qualitativa, ancorado no referencial teórico-metodológico da dialética (Minayo, 2015), que visa compreender os efeitos da multiplicidade de atribuições para a saúde da mulher, por meio de suas falas, possibilitando a realização de inferências e propor intervenções de modo a promover a saúde das mulheres.

Para este estudo, foi escolhida, intencionalmente, uma unidade da Estratégia Saúde da Família (ESF) da região sanitária sudeste do município situado na região do Centro-Oeste de Minas Gerais. A escolha do local se deu, dentre outros fatores, pela inexistência de estudos sistemáticos desta natureza no local e pela inserção da pesquisadora na ESF, onde atuava como residente do Programa de Residência em Enfermagem em Atenção Básica/Saúde da Família da UFSJ (RESENF).

A ESF de escolha engloba dois bairros, que são divididos em quatro microáreas, e é responsável por uma população de 2358 habitantes, sendo 1.202 do sexo feminino, e o total de 769 famílias, todas cadastradas no Sistema de Informação em Saúde. Em 2019, registrou-se o cadastro e o acompanhamento de 735 mulheres com idade entre 20 e 59 anos, que é a idade adulta, conforme definição da OMS (2011), na área de abrangência da ESF de escolha, que representa a população-alvo deste estudo (Divinópolis, 2020).

Foram elegíveis para o estudo as mulheres adultas da área de abrangência da ESF, que preenchiam os critérios de inclusão: maiores de 20 e menores de 59 anos, que exercem a função de donas de casa há pelo menos um ano, ter um ou mais filhos, e que exercem alguma atividade laboral fora do lar. A intenção foi compor uma amostra por conveniência, que tornou possível compreender a multiplicidade de papeis e seu impacto na saúde.

Os dados foram coletados a partir dos dados disponíveis no SIS, após autorização da Secretária Municipal de Saúde local. Para o levantamento das características demográficas e socioeconômicas, e para coletar os dados referentes às variáveis relacionadas à saúde, foi elaborado e aplicado um questionário padronizado para as mulheres. Posteriormente, foi realizado 
entrevista semiestruturada composta por oito questões.As entrevistas foram gravadas em áudio, com consentimento das participantes. O critério para que a coleta fosse finalizada foi a saturação de dados, estratégia utilizada em pesquisas qualitativas para estabelecer o fechar o tamanho de uma amostra (Fontanella et al., 2008).

A transcrição foi feita imediatamente após a gravação das entrevistas, para que se certificasse que os detalhes não fossem esquecidos e para que houvesse garantia que os mesmos fossem transcritos. Sabendo que existem diferentes maneiras de interpretar as falas, e transcrevê-las, os conteúdos das entrevistas foram transcritos considerando as características próprias da fala e seus diversos graus de detalhes. Para tal foi usada a convenção de transcrição sugerida por Koch (2010), mantendo elementos de registro oral como entonação, ênfase, pausa, silêncio, repetições, alterações na altura e no ritmo da fala. Para manter a privacidade das informações as entrevistadas foram identificadas com a letra E, seguido de numeral correspondente.

A análise dos dados foi feita a partir de recursos da análise de conteúdo, na perspectiva de Bardin. Para a autora o termo análise de conteúdo designa um conjunto de técnicas usadas para análise sistemática das comunicações visando a obter a descrição do conteúdo das mensagens, além de indicadores que permitam a inferência de saberes concernentes às condições de produção/recepção dessas mensagens (Bardin, 2016).

Para gerenciamento dos dados utilizou-se o software Atlas.ti (versão 8.4.22 de 13/12/2019), de apoio à análise de dados qualitativos. O software foi utilizado na análise de todos os dados a partir da consolidação do corpus, de modo a facilitar a criação das categorias de análise e a interpretação dos dados empíricos (Silva Junior \& Leão, 2018). A comunicação dos resultados do estudo obedece às diretrizes para relatórios de projetos de pesquisa de natureza qualitativa com uso de entrevistas e grupos focais disponível no COREQ (Consolidated criteria for reporting qualitative research) (Tong et al., 2007).

O projeto de pesquisa que deu origem a esse estudo (CAAE - 20653319.7.0000.5545) foi aprovado pelo CEPCO/UFSJ (Parecer n 3.612.031, de 01/08/2019), em concordância com a Resolução 466/2012/MS.

\section{Resultados}

Participaram do estudo 17 mulheres de 22 a 50 anos, brancas (47,1\%), pardas $(41,2 \%)$ e negras $(11,8 \%)$, a maioria com ensino médio (35,29\%), e ensino superior completo $(29,41 \%)$, casadas $(58,82 \%)$, solteiras $(11,76 \%)$ e união estável $(29,41 \%), 94,11 \%$ são católicas e 5,88\% protestantes, $47,06 \%$ possuem dois filhos, $29,41 \%$ possuem um filho, 17,65 três filhos e $5,88 \%$ quatro filhos.

Os resultados mostram que as condições socioeconômicas refletem a vulnerabilidade social do contexto em que vivem as participantes do estudo. As mulheres residem em casa própria (76,5\%), alugada $(17,6 \%)$ ou cedida $(5,9 \%)$, providas de água encanada, energia elétrica e coleta de lixo. Todas as mulheres tem acesso aos serviços públicos de saúde e $52 \%$ tem plano de saúde, convivem com 3 e 4 pessoas (64,71\%) e a renda familiar predominante é de 1 a 3 salários mínimos (64,71\% do total).

Cada mulher exerce uma função diferente no exercício laboral fora do lar, e a maior parte delas $(58,82 \%)$ exerce função com carga horária entre 5 e 8 horas por dia. A maioria não possui doenças crônicas $(76,47 \%)$, e não faz uso de medicamentos contínuos $(82,35 \%)$. Do total das entrevistas, $88,24 \%$ relataram realizar busca por informação de saúde, sendo a internet o meio mais utilizado, seguido de consulta a profissionais de saúde.

Nota-se que, apesar de $24 \%$ das mulheres do cenário afirmarem ser portadoras de doenças crônicas, apenas 18\% delas usam medicamento contínuo. Ressalta-se a tendência das mulheres em seguir o padrão sociocultural do contexto em que estão inseridas, principalmente no que diz respeito à paridade, nível educacional, carga horária de trabalho fora de casa, renda familiar e autocuidado.

Considerando o conceito ampliado, híbrido e plurifacetado de saúde, definido pela Organização Mundial de Saúde (OMS) e reforçado pela Organização das Nações Unidas (ONU) como "um estado de completo bem-estar físico, mental e social e não somente ausência de afecções e enfermidades", os dados empíricos revelam que, no cenário do estudo, os efeitos 
da multiplicidade de atribuições que mais influenciam na saúde das mulheres são os que comportam a relação com a casa e os afazeres domésticos, a relação com os filhos, com a família e com os grupos sociais e as relações com o trabalho. O autocuidado se mostra como desafio para a preservação do bem-estar e da qualidade de vida e manutenção do equilíbrio físico, social e mental.

\subsection{Repercussões das múltiplas atribuições na saúde das mulheres}

Para as participantes, a multiplicidade de atribuições deflagra sentimentos diversos e complexos, como sobrecarga, incompletude, responsabilidade, dependência, tristeza, angústia, frustração e insatisfação consigo mesma. Com o tempo, esses sentimentos, advindos de decisões ao longo da vida, tendem a causar desequilíbrios e estresse mental, que se manifesta em crises de ansiedade e depressão ou doenças físicas e acabam por repercutir no cuidado de si, na alimentação, na qualidade do sono, nos momentos de lazer e na prática de atividades físicas, num movimento cíclico vicioso, que se retroalimenta pela própria sensação de insatisfação de si mesma.

Nesse ínterim, a depressão, o estresse e o cansaço são referidos por diversas mulheres que desempenham múltiplas atribuições, com repercussões na saúde, no cotidiano da vida pessoal, na convivência familiar e profissional.

[...] a estafa foi me levando pra um quadro depressivo [...] foi pesando muito, eu tava impaciente até com meu filho. Aí que eu não tava com muita paciêncial eu não estava sabendo lidar com/ com o estresse que eu tava [...] eu ficava impaciente [...] até mesmo com as minhas clientes, com as pessoas ao meu redor. Por conta da carga excessiva de [...] obrigações né, era muita coisa, aí eu tava ficando meio perdida assim, com o tanto de atividade que eu tinha que fazer. (E1)

A sobrecarga de atividades provoca alterações na qualidade do sono e no padrão alimentar das mulheres, que, por vezes, deixa de se alimentar e descansar nos horários adequados, prejudicando sua saúde.

Eu não me alimento direito, eu não durmo direito, é, muito estresse é [...] eu como muita bobagem, [...] No tempo que eu tenho que comer,/ e aí acaba que come uma bolachinha, come um doce, come alguma coisa [...] só pra forrar o estômago e a alimentação saudável mesmo,/ não tenho. (E3)

Esse desequilíbrio ocasionado pelo excesso de trabalho acaba por influenciar na imunidade das mulheres e desencadear processos álgicos no corpo, de origem emocional.

Estresse nél, cansaço físico, psicológicol, corpo tem hora que dói muito, né, o físico, às vezes as pernas tá doendo muitol, mas muito, tem que tomar um comprimido, tomar um banho quente e deitar, ficar quietinha né, cabeça dói às vezes, de cansaçol, psicologicamente é o estresse mesmo e o cansaço mentall, às vezes eu fico nervosa, comigo mesmo, às vezes eu/ perco a paciência até comigo mesma, com meu marido né, com minha filha [...]. (E16)

Apesar da consciência da situação, a falta de organização dos afazeres profissionais e domésticos repercute, também, na prática do autocuidado, na prática de atividades físicas e em atividades de lazer, tornando-se um fator de risco para diversas patologias físicas e mentais em mulheres. 
É/, a gente esquece da gente né? A gente tem que lembrar que a gente também existe e que a gente precisa de cuidados. [...] Você fica preso naquela rotina, cê não tem tempo/ sua cabeça não foca em mais nada né. Então, você alimenta mal, você não conversa com ninguém, você não sai, você não tem vida. (E15)

[...] às vezes a gente come/ por ansiedade [...] eu/ eu não consigo manter uma rotina de atividade física, porque se eu tiro o tempo pra atividade física, não sobra tempo pra eu organizar as minhas coisas que eu preciso deixar organizado pra sair, pra trabalhar. [...] eu consigo fazer isso, manter minha casa arrumada, escola, dever, tudo em ordem, mas eu não consigo manter uma rotina de atividade física [...]. (E17)

O empoderamento feminino no mercado de trabalho e seu impacto na saúde da mulher se destaca nesse cenário. Ao mesmo tempo que a mulher se sente livre e realizada por exercer a sua função autora e criadora, atuando profissionalmente e adquirindo a independência financeira, o tempo dedicado ao trabalho e às relações interpessoais no ambiente laboral gera ansiedade e sensação de incompletude diante das cobranças e preocupações com as tarefas domésticas e o cuidado dos filhos, fruto da influência cultural sobre o papel da mulher do lar, cujas funções cuidadora, procriadora e educadora ainda se encontram arraigadas no imaginário social.

Os relatos sobre a rotina de trabalho evidenciam a pressão sofrida pela mulher relacionada ao tempo limitado para execução de cada tarefa, considerando o trabalho fora de casa, o cuidado com os filhos e o cuidado com as atividades domésticas.

Bem, durante a semana a minha rotina é bem corrida. [...] eu trabalho de manhã/ eu acordo sempre às seis da manhã e saio de casa por volta de dez pras sete por aíl [...] e eu volto na hora do almoço, [...] Então, de meio dia às onze da noite, eu sou mãe e dona de casa. [...] desde quando en tive o meu primeiro filho, eu deixei de trabalhar o dia todo. [...] Então, eu tive que cortar alguns gastos por esse motivo, então eu não tenho nenhuma ajudante na minha casa. À tarde e à noite eu cuido da minha casa, de roupa, de comida, dos meninos, e nél é o horário que eu tenho pra fazer tudo que eu tiver de fazer. [...] eu costumo dormir por volta de onze horas da noite, que é a hora que o meu marido tá chegando da faculdadel, que geralmente eu espero ele chegar e é ai que eu durmo. (E9)

Conflitos entre trabalho e família foram relacionados, associados principalmente a longas jornadas de trabalho, que se estendem para além do ambiente organizacional e também nos finais de semana. Para as mulheres o tempo gasto no trabalho impede que os compromissos pessoais ou familiares sejam realizados de forma efetiva.

[...] o que consome mais a hora da gente é trabalho né, que acaba que a gente colocal, faz oito horas por dia, mas [...] dá muito mais que oito horas né. Fora também que a gente fica acordando de madrugada, pensando no serviço [...] que geralmente é o que me dá insônial, me causa insônia, mas o que me ocupa mais é o trabalho [...]. (E13)

Além das extensas jornadas de trabalho, há relatos que deixam evidente a preocupação das mulheres com as exigências do trabalho, como a pontualidade. Esse é mais um fator gerador de ansiedade, que pode causar repercussões diretas nas relações interpessoais no ambiente laboral, além de aumentar o risco de acidentes.

[...] o excesso de trabalho, ainda mais quando eu não tinha filho, tinha o costume de levar serviço pra casa, e a gente fica querendo ajudar todo mundo né, fazer tudo pra todo mundo, querendo abraçar tudo e fazer nél, tentar resolver os 
problemas dos outros, e aí por conta disso, me deu estafa, que eu tive que ir no psiquiatra, tomar medicação por três meses né [...]. (E13)

Apesar do conflito entre trabalho e família, as mulheres buscam entender seu conjunto de papeis sociais com intuito de obter mais recursos, benefícios e valorização pessoal, por meio do enfrentamento das dificuldades encontradas, conciliando as responsabilidades de família e de trabalho. Assim, a ocupação profissional se torna uma forma de se sentir valorizada, ativa e de ter independência financeira.

Agora as vantagens do meu trabalho, é que é onde eu tiro o meu sustento, então eu posso dar um conforto melhor pras minhas filhas, colocar elas numa escola boa, de qualidade né? Ter um conforto em casa, comprar o que elas precisam, eu, a minha família toda né? Todos nós. (E11)

Assim, eu gosto dele, então ele impacta positivamente eu acho. Ele é gratificante pra mim. Eu gosto de vir trabalhar, eu gosto de ser reconhecida, eu gosto de ser valorizada, eu gosto de atender as pessoas, eu gosto de trabalhar com saúde. (E9)

Não obstante os avanços e conquistas no universo feminino, a dedicação às tarefas domésticas ainda se mostra como atividade mais importante para as mulheres no contexto do estudo, que é evidenciando como modelador da identidade feminina e como um ambiente onde elas podem exercer autonomia e poder.

[...] cuidar da casa, famílial, eu acho mais importante é isso, porque se eu perder o controle da minha casa eu não fico bem pra trabalhar fora, entendeu? [...] Tanto que eu só optei por trabalhar meio horário por isso, porque o horário integral eu não tava conseguindo [...]. Cuidar da casa, das obrigações/ né, das obrigações de casa, filho, e ficar o dia todo fora. Tava ficando ansiosa, tava perdendo o controle mesmo, então eu trabalho meio horário. (E17)

A dedicação de grande parte de tempo aos afazeres domésticos tem gerado sobrecarga de trabalho para as mulheres e repercussões na saúde. Dividir as tarefas domésticas com os demais moradores da casa tem-se mostrado uma saída favorável à manutenção da qualidade de vida das mulheres.

[...] Eu tenho muita sorte né, [...] que meu marido me ajuda demais, [...] em relação ao filho. Se eu tô fazendo alguma coisa e o menino chorou, ou tá com fome, ele me ajuda, então não precisa de eu pedir nada, ele mesmo já sabe. [...] isso me descansa, mas mesmo assim a gente fica él, estressado, por causa desse excesso mesmo. (E8)

Há evidências da presença do discurso da responsabilidade familiar feminina, com destaque para os deveres intrínsecos da mulher no cuidado do outro. Destaca-se, nesse contexto, o papel do suporte social e familiar no universo feminino.

Ai eu acho ser mãel, ser mãe e ser esposa. Porque a gente tem que tirar um tempinho mesmo com a correria [...] de dar aquele tempo, aquela atenção pro marido, porque eles cobram/ muito, atenção nél, e, os filhos principalmente, em primeiro lugar [...] a gente tem que tá ali presente [...]. (E16) 
$\mathrm{Na}$ tentativa e conciliar os inúmeros papeis sociais impostos, a mulher tem sua rotina sobrecarregada, o que acaba prejudicando a prática do cuidado, as relações e o suporte familiar.

Sinto, muito, porque se eu for pensar, a gente tem que ser esposa, mãe, filha, porque minha mãe mora do lado e sozinha agora, porque meu pai morreu, [...] então minha mãe tá sozinha, então ela quer conversar, ela quer atenção, então ela vai lá pra casa né, e a maioria das coisas dela quem resolve sou eu [...]. (E11)

Os achados reforçam a ideia de que as mulheres são mais vulneráveis à violência doméstica que os homens. Isso se deve, principalmente, às diferenças de gênero estabelecidas pela sociedade no decorrer dos anos, e reflete um problema ainda maior ao considerar as múltiplas atribuições relacionadas à assimetria de poder que colocam as mulheres em uma posição de submissão, levando em conta que os papeis masculinos muitas vezes são mais valorizados. Nesse contexto, o relacionamento conjugal constitui um importante aspecto das relações estabelecidas dentro do espaço doméstico. Nessa conjuntura, há relatos de dinâmicas conjugais conflitivas e disfuncionais, e outras que são marcadas pelo controle, o que contribuiu para o afastamento da mulher de atividades de lazer.

[...] quando eu era casadal eu tive um problema devido o jeito que o meu marido me tratava, aí esse foi o motivo da minha separação. Isso causou tudo na minha vida, eu vi que eu estava ficando mal [... ] e eu tive essa decisão, de separar pra mim sentir bem comigo mesma. Não foi fácil pra mim, porque tinha minha filha, mas eu não podia pensar só nela [... ]. (E14)

Meu marido é muito ciumento sabe, e machista, então assim, ele não me dá essa liberdade [...] então assim, eu também não faço, sabe assim, de sair sem ele. [...] (E16)

As participantes deixam claro as repercussões da maternidade na vida e na saúde das mulheres, sendo o cuidado com os filhos a atividade considerada a mais importante, reforçando o papel social de procriadora, cuidadora e educadora. A prática da maternidade além de ser vista como prioridade, é realizada sob a forma de cuidado contínuo. A mulher acredita que poder cuidar dos filhos pessoalmente é importante.

Mais importante? Levar meu filho pra escola, dedico/ o pouco tempo que eu dedico à ele, pra mim é a atividade mais importante que eu faço, embora seja a que eu menos pratico né? Pelo fato de não ter tempo. (E3)

A mais / a coisa mais importante da minha vida é meu filho né. Assim, eu trabalho muito por causa dele. Por causa que ele fica muito sozinho/ eu acho que ele fica muito sozinho né. Porque eu tenho que trabalhar. (E7)

No cenário, evidenciou-se a mudança de rotina após a inclusão da maternidade na vida cotidiana, tornado esse papel prioridade.

[...] meu marido é a base de sustento, pra trazer o sustento, e eu querendo ou não, eu sou a aquela quel que controla, que ajeita, que faz tudo né, principalmente agora que sou mãe, então/ é a mais importante que tem pra mim, é amamentar a (filha), sempre bem cuidada, tudo/ manter nél é o horário dela de sono em dia, essas coisas. (E2) 
Os dados empíricos revelam que a conciliação dos diversos papeis causa diversas repercussões na vida da mulher, e a repercussão na prática do cuidado com os filhos foi um dos problemas mais citados.

O impacto maior que causa o trabalho, é justamente a educação do meu filho, que várias vezes/ eu já ouvi ele, uma criança de seis anos, falar pra mim que não quer ficar comigo, por que eu não tenho tempo pra ele, que queria morar com o pai dele, por causa que realmente eu não tenho tempo pra ele[...]. (E3)

O ponto negativo do trabalho, é que a gente fica muito tempo no trabalho e não fica quase nada com a família né, o (filho)/, eu trabalho desde quando ele era bebezinho, então eu não/ eu perdi praticamente o crescimento dele [...]. (E10)

\subsection{Desafios para a preservação da saúde e da qualidade de vida das mulheres}

A sobrecarga de trabalho, advinda dado desempenho de múltiplas atribuições ao longo da vida, gera desconfortos na vida das mulheres no contexto deste estudo. Neste cenário, as mulheres apresentam diversas queixas advindas dessa multiplicidade de atribuições:

Eu acho que o tempo que a gente fica por conta do serviço, toma o tempo que a gente poderia fazer outras coisas, porque aí esse tempo que sobra que eu não tô no trabalho, eu tô cuidando de casa e dos filhos, então se eu tivesse um tempo menor, no trabalho, eu poderia fazer um outro tipo de atividade que fosse pra mim [...]. (E12)

[...] E me cansa muito ter que cuidar de tudo né. Eu to numa fase na minha casa, que eu cuido de tudo da casa, se eu tenho/ às vezes eu chego em casa e não tem um copo limpo [risos], tipo/ aí às vezes desgasta muito [...]. (E9)

Para as mulheres deste estudo, o tempo despendido nas atividades diárias, influencia para que algumas coisas fiquem em segundo plano, mostrando a importância do planejamento e organização eficiente do tempo para a realização das tarefas.

Ah sim, nesse sentido de cansaço sim. É/ às vezes eu fico bem cansada, por mais quelque é poucas horas trabalhadas né, mas eu fico bem cansada, porque é muita coisal às vezes a gente não da nem contal não sabe nem o que que começa a fazer primeiro. Então assim, aquela rotina que a gente já tinha programado [...] atrapalhada em questão disso, das atribuições do serviço. (E8)

Na busca pela manutenção do equilíbrio físico, social e mental, da liberdade, independência, autonomia, segurança, satisfação pessoal e realização profissional, as mulheres tem buscado respeitar os limites individuais e a aceitação do suporte e apoio social nas atividades cotidianas. Nesse ínterim, na visão das participantes, investir na prática do autocuidado é considerada como atividade importante para aumentar a autoestima e o autoempoderamento feminino e, por conseguinte, favorecer a promoção da saúde e o bem-estar das mulheres.

Muito cansaço, eu ficava muito cansada, muito nervosa. O estresse do/do meu trabalho era muito grande. E aí eu procurei a meditação por causa disso. E aí com essa prática, aí eu fui reduzindo a minha carga horária, um pouco do trabalho, aprendendo a lidar melhor com as clientes, com o meu meio de vida/ com o meu meio. (E1)

Eu acho que quando a gente não tem uma válvula de escape, pra poder é, esvaziar a cabeça, desestressar, mudar de foco, descansar, fica mais pesado no fim do dia, no fim do mês, no fim do ano, vai ficando tudo mais puxadol, mais 
cansado. E aí a gente começa às vezes a adoecer uma pouco mais, fica mais fragilizado, começa a ficar mais estressado, perde a paciência com os filhos às vezes mais rápido. E aí, talvez essal, se eu tivesse mais tempo del, de lazer [...] com certeza ficaria mais leve. Mas, nesse último ano, eu não tenho conseguido fazer isso muito não. (E9)

Os cuidados com o corpo, aliados à prática de meditação e atividades físicas são destacadas por quatro mulheres para a manutenção da autoestima, da saúde e do bem-estar. Apesar da importância do autocuidado para a saúde, há evidência que essa prática nem sempre é vista de maneira positiva pelos familiares e por pessoas próximas.

[...] Pra mim a saúde física e mental é a mais importante [...]. A meditação sem dúvida pra mim é a melhor. [...] $O$ que eu mais fiz foi o Muay thai. Esse ano eu fiz/ eu lutei muito. Fiz muita Ioga, muita meditação. E trabalhei bastante também. Mas esse ano foi um ano que eu tirei mais coisa pra fazer pra mim mesmo. Ai eu fiz bastante práticas para mim assim. [...] É difícil porque a maioria das pessoas não entendem o quel que é a meditação, não entende o quão bom para mim é. [...] o tanto que me faz bem. (E1)

As atividades de lazer e as relacionadas à espiritualidade se mostram significantes na proteção da saúde mental das mulheres no contexto. Essas atividades de entretenimento tiram a mulher da rotina, que, por vezes, é exaustiva, advinda da sobrecarga de atribuições.

[...] Às vezes minha mãe busca os meus meninos, aí eu fico em casa, vejo um filme né, ou faço uma comida diferentel, aí fica eu e meu marido/, então/ eu passeio com os meninos também/ eu desestresso com eles também. (E5)

A igreja também, acaba que a religião também ajuda bastante né [...] o que mais me ajuda eu acho que é primeiro Deus né, lógico, depois atividade física eu acho que me ajuda bastante. (E13)

Para vencer o desafio da multiplicidade de atribuições é preciso investir na organização eficiente do tempo para a realização das atividades diárias, de modo a conciliar a vida pessoal, familiar e profissional. É preciso dar ênfase na manutenção do autocuidado, da organização da rotina de trabalho, das tarefas domésticas e a convivência com a família e amigos, evitando os conflitos e o mal-estar, superando a sobrecarga de atribuições de maneira positiva, associada à satisfação pessoal e manutenção da saúde.

[...] Hoje tá mais tranquilo, assim, que eu consegui a/ alinhar as coisas, ter tempo pra tudo, ter tempo pra mim, ter tempo pra ser mãe, ter tempo pra ser mulher, ter tempo para ser uma menina sem nada também. Agora eu consigo, agora eu to super bem assim, com tudo, tanto profissionalmente, quanto com a minha vida materna, com a minha vida pessoal também, agora tá tudo mais tranquilo. (E1)

\section{Discussão}

A essência feminina se manifesta na representação imbricada de diversas atribuições, de trabalhadora, progenitora, esposa, dona de casa e cuidadora, além das responsabilidades advindas do gênero, cujas influências tem consolidado a definição cultural dos papeis da mulher na sociedade. O desempenho de cada uma dessas funções são formadoras da natureza feminina e o ato de exercer os afazeres domésticos, por exemplo, é visto, por vezes, como o espaço onde ela pode exercer sua autonomia, o que aumenta a importância dessa tarefa para muitas mulheres. Estudos corroboram essa afirmação, e reitera que, 
mesmo com as mudanças atuais, onde o homem tem se tornado cada vez mais participativo nestas atividades, percebe-se que, majoritariamente, as tarefas domésticas ainda são de particularidade feminina (Simao, 2019; Braga et al., 2019).

Considerando as questões de gênero e de definição de papeis, vê-se uma dificuldade, por parte da mulher, quando se trata da divisão das tarefas domésticas com os demais moradores da casa. Essa dificuldade de aceitar ajuda se traduz em sobrecarga de atribuições para mulher e acúmulo das tarefas indefinidamente, levando a um ciclo vicioso que a prejudica em diversos âmbitos da vida. Estudo confirma a desigual divisão das tarefas domésticas, e da sobrecarga da mulher, em especial para as casadas e com filhos, e comprova que o ambiente do lar é uma esfera da dinâmica do poder masculino. Além disso, ressalta que a presença do homem em casa, na maior parte das vezes, não representa cooperação ou distribuição de tarefas entre os demais moradores da casa, mas sim se traduz no aumento do trabalho invisível e não remunerado da mulher no ambiente doméstico (Vieira et al., 2020). Acredita-se que a divisão das tarefas domésticas com os demais moradores da casa pode ajudar a mulher a esquivar de repercussões negativas da sobrecarga, proporcionando mais qualidade de vida.

Nesse contexto, ressalta-se a responsabilidade familiar, que trata sobre a reprodução e manutenção da família, cujos achados revelam que essa é outra tarefa colocada como de responsabilidade privativamente feminina. A literatura traz o questionamento acerca do senso coletivo que mostra que a mãe é a única responsável por zelar pela família, em particular pelos filhos, onde é evidente a importância do cuidado no desenvolvimento físico e psíquico destes. Nesse ínterim, o papel da mulher é posto a prova, visto que ela precisa arcar com as responsabilidades que lhe são impostas e provar para a sociedade, que nem sempre lhe favorece, que é capaz dar conta de tudo sozinha. Sabendo disso, é necessário ressaltar que deve haver uma redistribuição dessa tarefa, pois a responsabilidade familiar não pode estar somente a cargo das mulheres. É indispensável repensar, como sociedade, sobre os papeis dos autores envolvidos nesse cuidado, responsabilizando igualmente os pais, independente do gênero (Ziwchak\& Aristides, 2019).

Outra atribuição que tem implicações na saúde da mulher é a maternidade, entendida como um evento que modifica a vida do casal, especialmente a vida da mãe pós moderna, que geralmente assume a maior parte das responsabilidades do cuidado dos filhos, e que considera esta como a responsabilidade mais importante de toda a rotina (Zanettini et al., 2019). Por ser um cuidado contínuo, muitas vezes traz repercussões para a vida das mulheres, e, sabendo disso, torna-se importante a investigação dos sentimentos e vivências dessas mães, especialmente aqueles relacionados a situações estressantes. Essa exposição do lado difícil da maternidade, por vezes, é negligenciada na sociedade, em decorrência dos estereótipos que tendem a destacar o lado singelo, bom e bonito, sendo que, nem sempre é aceito que a mãe possa ter dificuldades legítimas e que possa se sentir sobrecarregada ao cuidar dos filhos.

Devido à dupla jornada de trabalho, a mulher se sente cansada e até mesmo culpada, porque, ao buscar a realização profissional fora do lar, acaba por não conseguir dividir o cuidado dos filhos e as tarefas domésticas, gerando a sobrecarga de trabalho e o acúmulo de funções. Estudos corroboram tal achado, e ainda acrescentam o fato de que, quando as mulheres optam por seguir a vida acadêmica, isso acaba por configurar uma tripla jornada de trabalho (Braga et al., 2019). A vida acadêmica introduz na rotina uma tarefa ainda mais difícil, que demanda tempo e dedicação além da habilidade de conciliar esse três segmentos.

O desempenho de uma tripla jornada de trabalho é uma tarefa difícil, pois traz à mulher uma mescla de sentimentos em relação às diferentes cobranças impostas pela família, e é, por vezes, motivo de sofrimento emocional. Isso acontece porque a mulher passa a ter o seu tempo ainda mais cronometrado para cada tarefa, e os familiares acabam por cobrar carinho e atenção, o que gera, nessa mulher, um sentimento de culpa e frustração (Costa, 2018). Por mais que as mulheres entendam que é difícil exercer todas as atribuições com excelência, elas buscam realizá-las da melhor forma que conseguem, e, quando se deparam com as exigências familiares, a sensação de impotência e de desgaste se tornam eminentes. 
Em todo esse processo de conciliação de tarefas, a mulher sofre mais cobranças, pois enfrentam as duplas ou triplas jornadas de trabalho, e essa conciliação entre vida familiar, acadêmica e profissional provoca, nas mulheres, sentimentos por vezes contraditórios. A falta de tempo para a família e a dificuldade de acompanhar o crescimento dos filhos é vista, pela mulher, como sentimento de perda, que é uma consequência da herança da responsabilidade familiar feminina, porém, essa mulher não quer retroceder unicamente ao espaço privado do lar, mas, também, não quer abandonar o trabalho, e quer, a qualquer custo, dar conta de tudo (Costa, 2018).

A mulher, diante dessa multiplicidade de atribuições, tem buscado, cada vez mais, incorporar estratégias para a manutenção do equilíbrio físico social e emocional, e, diante disso, tem procurado entender e respeitar seus limites individuais, além de investir no autoconhecimento e no cuidado de si. Diante disso, aceitação do suporte e do apoio social é evidente, e essa nova possibilidade se traduz em mudanças na vida familiar e social e possibilita avanços na ressignificação do papel da mulher na sociedade.

Entende-se o apoio social como uma rede de sistemas e de pessoas significativas, que proporcionam amparo ao indivíduo diante de situações de vida. Esse apoio pode se dar por meio de manifestações de encorajamento e assistência, provida por familiares, amigos, profissionais ou outras pessoas, com intuito de promover auxílio emocional, de recursos ou de informações (Rocha et al., 2019). Ademais, é possível elucidar que, quando a mulher aceita a ajuda e apoio de outras pessoas, os sentimentos de autoconfiança, autonomia e realização pessoal tendem a aumentar. Nesse sentido, torna-se possível identificar e trabalhar questões emocionais envolvidas, que poderiam propiciar repercussões negativas futuras e esquivar-se ou empoderar-se para o enfrentamento dessas situações de forma preventiva.

Nesse espaço, é importante ressaltar a importância do autocuidado, uma vez que esse é, por vezes, negligenciado pelas mulheres, que, diante da sobrecarga de atribuições citam o tempo (ou a sua falta de organização) como um impeditivo, não conseguindo organizá-lo de modo a dispor de espaço para o cuidado com sua aparência e saúde (Comes et al., 2020). Estudos comprovam a importância da abordagem do autocuidado, que está intimamente ligado à satisfação pessoal, e descreve que, muitas vezes, as mulheres tem consciência de que o cuidado de si é omitido diante das inúmeras atividades desenvolvidas, e há relatos de que as mulheres programam-se para tal, mas acabam por postergar em detrimento de outras atividades consideradas mais urgentes (Piolli et al., 2018; Soaigher et al., 2016).

Acredita-se, com base nos dados empíricos, que o desenvolvimento da mulher na sociedade trouxe consigo algumas consequências como a falta de tempo, citada diversas vezes como um problema neste estudo. Ao assumir uma vida com dupla ou tripla jornada de trabalho, a mulher acaba se vendo forçada a dedicar-se mais aos filhos e aos afazeres domésticos, postergando, por vezes o investimento no seu desenvolvimento pessoal e profissional, ou ao contrário, dedicam-se mais ao lado profissional e culpam-se por deixar as demais atribuições domésticas em segundo plano (Braga et al., 2019). É possível ver, nesse contexto, mulheres com dificuldades de equilibrar suas vidas pessoais e seu tempo de forma efetiva. Em uma realidade de dupla jornada de trabalho vê-se que, geralmente, as mulheres dedicam todo o seu tempo e energia diária priorizando atividades urgentes, e quase não despendem atenção às atividades que, de fato, trariam resultados importantes para suas vidas, como alimentação saudável, atividades físicas, de descanso e lazer.

Essa priorização de atividades urgentes causa uma propensão ao estresse, deixando a mulher vulnerável. Isso ocorre porque a mulher não possui, por vezes, a devida instrução de como administrar o tempo de forma correta, que, basicamente, consiste na reprogramação dos pensamentos para realizar primeiro as tarefas importantes, evitando que se tornem urgentes. Estudo mostra que, para a organização efetiva do tempo, prevê-se a definição de metas, o planejamento, a organização e a execução, onde este último retrata o momento em que tudo será posto em prática (Michelatoyoshiy \& Kienen, 2018). Sabendo disso, é possível facultar às mulheres uma sugestão de melhoria na forma de gerir seu tempo de forma eficiente, e com essa ferramenta, conseguir se adaptar para enfrentar os desafios diários que podem surgir. 
Esse estudo revela que a falta de organização das atividades diárias, e as múltiplas tarefas diante do tempo curto faz com que as mulheres se sintam tristes e angustiadas, o que acarreta, em alguns casos, processos álgicos e até patológicos. Essas questões geram questionamentos sobre as escolhas feitas durante a vida, e essas mulheres, ao se darem conta da temporalidade da sua existência, acabam não vendo muito sentido para os dias que virão. Esse achado é corroborado por estudo que diz que esse ciclo de escolhas e possibilidades revela que o fato de ser mãe, esposa, dona de casa, mesmo que isso seja um desdobramento da condição feminina imposta na sociedade, vem como uma dimensão dos interesses socioeconômicos que são ditados à essas mulheres, que ao assumirem esse papel, acabam por limitarem sua existência (Santos \& Diniz, 2018).

Dessa forma, percebe-se que o autocuidado alinhado com a organização da rotina e com a gestão do tempo disponível tem se mostrado como forte aliado na manutenção da segurança, liberdade e satisfação pessoal, qualidades ligadas diretamente à qualidade de vida das mulheres. Esses achados revelam uma possibilidade de burlar o ciclo vicioso, superando a sobrecarga de atribuições de forma positiva, onde é possível perceber que a inclusão do lazer, a prática do autoconhecimento e do autocuidado favorece uma rotina menos maçante e uma mentalidade mais resiliente.

Nesse contexto, há necessidade de fomentar estratégias para o estímulo ao autoempoderamento, o que beneficia a manutenção da saúde física, social e mental, evitando ou enfrentando favoravelmente as situações conflitantes e, consequentemente dando sentido e significado para os dias vindouros das mulheres.

\section{Considerações Finais}

Ao longo dos tempos, as mulheres, ao assumirem diversos papeis, acabam por negligenciar sua função criadora e autora da própria vida, deixando para segundo plano o cuidado de si em detrimento do cuidado do outro quer seja no trabalho, na família, no casamento ou na maternidade. Em suma, essa dinâmica constitui-se como um sentimento de ambivalência, em relação à conciliação entre trabalho, vida pessoal e familiar, com uma busca constante de realização, e o desejo de cumprir com todas as exigências da autonomia individual, sem desvencilhar-se do seu lugar de liderança nas atividades domésticas.

Diante desses desafios é necessário fomentar a reflexão sobre como a mulher irá viver cada um desses papeis, investindo na definição do plano de vida e na gestão do tempo, de modo a favorecer a realização profissional, sem desconsiderar a satisfação pessoal (física e emocional) e a convivência harmoniosa com os filhos e com a família, pois ao cuidar de si, acaba por cuidar melhor do outro. Os relatos e o conhecimento de cada realidade tornam-se necessário para o adequado planejamento de ações voltadas à saúde da mulher, de forma a reduzir o prejuízo para a qualidade de vida em todo o ciclo de vida feminino.

Nesse sentido, a educação em saúde vem como um recurso e como um processo político e pedagógico, que pleiteia o desenvolvimento de um pensar reflexivo e crítico, permitindo desvelar a realidade e propor ações transformadoras, que leva a mulher a gestão da sua autonomia, a flexibilização da vida em todos os seus âmbitos e a emancipação como sujeito histórico e social, capaz de propor e opinar nas decisões de saúde para promover seu autocuidado, cuidar de sua casa, de sua família, e do seu trabalho. Práticas educativas nos serviços de saúde devem ser realizadas com esta visão, e devem sem incluídas na rotina dos profissionais de saúde, e serem implementadas nas diretrizes do SUS. Destaca-se, ainda, a necessidade de se pensar em políticas públicas que possam fornecer melhores condições para essas mulheres, que necessitam vivenciar duplas ou triplas jornadas de trabalho.

Dentre as possíveis contribuições desse estudo, destaca-se a importância de os profissionais de saúde, os gestores e a sociedade em geral, de entender as implicações que a multiplicidade de atribuições pode causar na vida e saúde das mulheres, e, a partir do entendimento destas questões, proporcionar estratégias de acolhimento para este público. Estas se justificam porque diante do cenário atual, onde as mulheres vivenciam essa realidade, acaba por constituir uma perspectiva que demanda uma atenção diferenciada, visto que a qualidade de vida, nesse ínterim, é o mais importante. 
Diante de tal compreensão é premente a necessidade de outros estudos que abordem a presente temática, a fim de aprofundar as vivências de mulheres com múltiplas atribuições, e propor ações de cuidado que visem a singularidade e a integralidade da mulher.

\section{Referências}

Bardin L. (2016). Análise de conteúdo. Lisboa, Portugal: Edições 70, LDA.

Barreto, M. L. (2017). Health inequalities: a global perspective. Cien Saude Colet, 22(7), 2097-2108.

Bezerra, J. F., Lara, S. R. G., Nascimento, J. L. \&Barbieri, M. (2018).Care for women subjected to sexual violence and public health policies: an integrative literature review.Rev Bras Promoç Saúde, 31(1), 1-12.

Bhattacharya, A., Camacho, D., Kimberly, L. L. \& Lukens, E.P. (2019). Women's Experiences and Perceptions of Depression in India: A Metaethnography. Qualitative Health Research, 29(1), 80-95.

Braga, N. L., Araujo, N. M. \& Maciel, R. H. Working conditions of women: An integrative review of Brazilian literature. Psicol. teor. prat. 2019; 21 (2): 232251 .

Brasil. Ministério da Saúde. (2004).Política nacional de atenção integral à saúde da mulher: princípios e diretrizes. Brasília (DF): Secretaria de Atenção à Saúde. Departamento de Ações Programáticas Estratégicas. https://bvsms.saude.gov.br/bvs/publicacoes/politica_nac_atencao_mulher.pdf

Costa, F. A. (2018). Women, work and family: the impacts of work in women's subjectivity and in its family relationships.Pretextos, 3 (6), 434-452.

Comes, Y., Pereira, L. L., Sima, P., Ribeiro, I., Vivas, G. \& Rosales, C. (2020). Women's health and empowerment: a study of case of the More Doctors Program in municipalities with presence of Cuban doctors. Rev Panam Salud Publica, 44, 1-7.

Divinópolis. (2020). Sistema de Informação em Saúde (SIS). Divinópolis (MG): Secretaria Municipal de Saúde.

Fontanella, B. J. B., Ricas, J. \& Turato, E. R. (2008). Saturation sampling in qualitative health research: theoretical contributions.Cad. Saúde Pública, 24(1), $17-27$.

Hay, K., McDougal, L., Percival, V., Henry, S., Klugman, J., Wurie, H., ... Raj, A. (2019). Disrupting gender norms in health systems: making the case for change. Lancet, 393 (10190), 2535-2549.

Heymann, J., Levy, J. K., Bose, B., Ríos-Salas, V., Mekonen, Y., Swaminathan, H., ... Darmstadt, G.L. (2019). Improving health with programmatic, legal, and policy approaches to reduce gender inequality and change restrictive gender norms. Lancet, 393 (10190), $2367-2377$.

Koch, I.V. (2010). A inter-ação pela linguagem. São Paulo: Contexto.

Michelatoyoshiy, S. \& Kienen, N. (2018). Time management: a behavior analysis interpretation. Psicol. educ., 47, 67-77.

Minayo, M. C. S. (2015). Pesquisa social: teoria, método e criatividade. 34ta edição. Petrópolis: Vozes.

Organização Mundial de Saúde (OMS). (2011). Mulheres e saúde: evidências de hoje, agenda de amanhã. http://biblioteca.cofen.gov.br/wpcontent/uploads/2021/04/mulheres-saude-evidencias-hoje-agenda-amanha.pdf

Pedrosa, M. \&Zanello, V. (2016). (In)visibility of violence against women in mental health. Psic.: Teor. e Pesq., 32 , 1-8.

Piolli, K. C., Decesaro, M. N. \&Sales, C. A. (2018). (Not) taking care of yourself as a woman while being a caregiver of a partner with cancer. Rev Gaúcha Enferm, 39 (e2016-0069), 1-7.

Rabelo, A. R. M. \& Silva, K. L. (2019). Care of the self and power relations: female nurses taking care of other women. Rev. Bras. Enferm., 69 (6), 12041214.

Rocha, R. Z., Galeli, P. R. \&Antoni, C. (2019). Social and affective support of women who have experienced intimate partner violence. Contextos Clínicos, 12 (1), 124-152.

Samosir, O. B., Kiting, A. S. \& Aninditya, F. (2020). Role of Information and Communication Technology and Women's Empowerment in Contraceptive Discontinuation in Indonesia. J Prev Med Public Health, 53(2), 117-125.

Santos, L.S. \& Diniz, G.R.S. (2018). Mental health of houseWives: a feminist-phenomenological-existential perspective. Psicol. clin., 30(1), 37-59.

Senicato, C., Azevedo, R.C.S. \& Barros, M.B.A. (2018). Common mental disorders in adult women: identifying the most vulnerable segments. Cien Saude Colet, 23(8), 2543-2554.

Silva Junior, L. A. \& Leão, M. B. C. (2018). Atlas.ti software as a resource for content analysis: analyzing robotics in science teaching in Brazilian theses. Ciênc. educ. (Bauru), 24(3), 715-728.

Simao, A. B. (2019). Between the ideal and the real: perceptions and practices about the division of domestic and care activities in Brazil. Rev. bras. estud. popul., 36(e0078), 1-7.

Soaigher, K. A., Acencio, F. R. \& Cortez, D. A. G. (2016). The power of vanity and self care in quality of life. Cinergis, 18(1), 69-72. 
Research, Society and Development, v. 10, n. 12, e376101220415, 2021

(CC BY 4.0) | ISSN 2525-3409 | DOI: http://dx.doi.org/10.33448/rsd-v10i12.20415

Tong, A., Sainsbury, P. \&Craig, J. (2007). Consolidated criteria for reporting qualitative research (COREQ): a 32-item checklist for interviews and focus groups. Int J Qual Health Care, 19(6), 349-357.

Vieira, P. R., Garcia, L. P. \& Maciel, E. L. N. (2020). The increase in domestic violence during the social isolation: what does it reveals?. Rev. bras. epidemiol., 23(e200033), 1-5.

Vilela, N. G. S. \& Lourenço, M. L. (2018). Work-Family Conflict: A Multiple Case Study with Working Women.Pensando fam., 22(2), 52-69.

Zanettini, A., Urio, A., Souza, J. B. \&Geremia, D. S. (2019). The Motherhood Experiences and the Conception of Mother-Baby Interaction: Interfaces Between Primiparous Adult Mothers and Adolescents. J. res.: fundam. care. 2019; 11(3), 655-663.

Ziwchak, D. J. V. \&Aristides, J. L. (2019). Perception of family members regarding their role in caring for the child and adolescent users of a CAPS for children and adolescents. Arq. Ciênc. Saúde UNIPAR, 23(3), 181-187. 